\title{
SEXUAL SIZE DIMORPHISM IN STONE MARTEN (MARTES FOINA, ERXL. 1777) FROM SARNENA SREDNA GORA MTS (BULGARIA)
}

\author{
S. Peeva* \\ Department of Animal Production - Non-Ruminants and Other Animals, Faculty of Agriculture, \\ Trakia University, Stara Zagora, Bulgaria
}

\begin{abstract}
Sexual dimorphism in body size measurements of 65 stone martens was investigated in winter periods (10.12.- 01.03) 2013 to 2017. There was found sexual dimorphism in body size of Stone Marten from Central Bulgaria: males were larger than females. The tail length (with or without hairs) did not depend on sex. The sexual dimorphism in the most variable linear parameters of the species varied from $2.76 \%$ to $10.63 \%$. Male stone martens were $23.37 \%$ heavier than females.
\end{abstract}

Key words: linear parameters, body weight, compactness index

\section{INTRODUCTION}

The existence of differences in body size and body mass between males and females across various animal taxa is of interest for many researchers. The most basic morphological characteristic used for analyzing sexual dimorphism is body size (1). There are three hypotheses explaining these differences. The first one considers sexual dimorphism to be connected to different food sources (2). According to some authors both sexes differ in size because of reasons related to reproduction $(3,4)$. The third hypothesis suggests that smaller females have the advantage of being more energy-effective. Thus, they can save more energy for the processes of growing cubs (4).

In the smallest mustelid - weasel (Mustela nivalis), "the best size to be is not the same for both sexes" - males are always bigger (5). Among all mustelid species inhabiting Bulgaria, the badger (Meles meles) is the biggest. The range of body weights and body lengths was reported to overlap considerably between both sexes in this species (6).

\footnotetext{
*Correspondence to: Stanislava Peeva, Department of Animal production - Non-ruminants and other animals, Faculty of Agriculture, Trakia University, 6000 Stara Zagora, Bulgaria, E-mail: st.peeva@abv.bg
}

The Stone Marten (Martes foina Erxl., 1777) is medium-sized carnivore species from family Mustelidae. It occupies a remarkable variety of habitats in Bulgaria - from plains to mountains and urban territories. The species is a hunting object (7). Although wide distribution of the Stone Marten, data about biometry are still scarce in Bulgaria. Some external measurements concerning biometry are included in "Mammals in Bulgaria" (8) and "Fauna Bulgaria" (9), without sexual dimorphism to be taken into account.

\section{STUDY AREA}

Geographic variation in sexual dimorphism has been described for many mustelids $(10,11,4)$. The study area is located in Central Bulgaria near Stara Zagora city $\left(42^{\circ} 24-34^{\prime} \mathrm{N}, 2^{\circ} 16\right.$ $56^{\prime} \mathrm{E}$ ) and covers a part of Sarnena Sredna Gora Mts (Figure 1). In the region woodlands are alternating with arable lands, comprising villages. The terrain is hilly with an elevation between 350 and $900 \mathrm{~m}$ a.s.l. The climate is classified as mild according to the KoppenGeiger Climate Classification - Dfb code (12). The area certainly provides suitable habitat for the Stone Marten. 


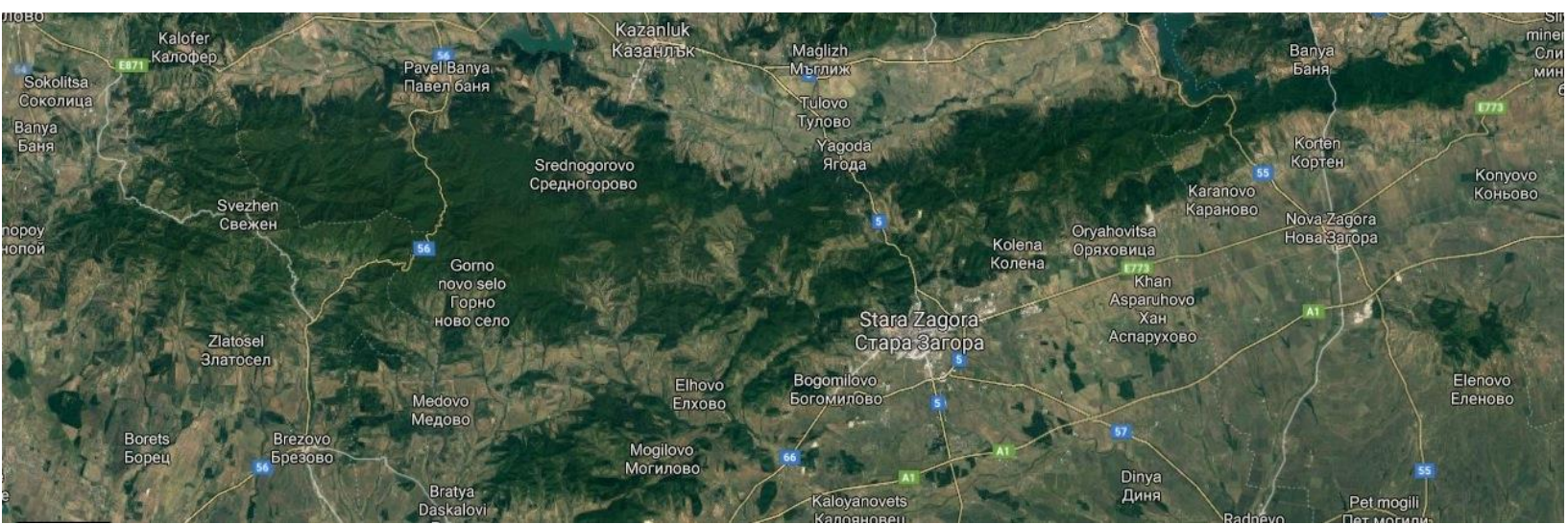

Figure 1. Study area - a part of Sarnena Sredna Gora Mts

\section{MATERIAL AND METHODS}

Body size measurements were based on 65 stone martens (41 males and 24 females). The carcasses were provided by hunters in the Taxidermy laboratory of the Faculty of Agriculture at Trakia University in winter periods (10.12 - 01.03) 2013 to 2017.

A total of 12 linear parameters and the body weight of sampled animals were taken following 13:

- Total body length from the tip of snout to the tip of the tail along the backline (TBL)

- Total body length from the tip of the snout to the tip of the tail sideways of the body (TBLs)

- Body length from the tip of the snout to the base of the tail along the backline (BL)

- Body length from the tip of the snout to the buttock (sideways of the body) - straight body length (BLs)

- Length of the tail with hair (LTh)

- Length of the tail to the last sacral vertebra (LT)

- Fore limb length from the withers to the ulnar tuberosity (FLL1)

- Length of fore limb from the elbow to the nail tips (FLL2)

- Length of hind limb from the knee joint to the nail tips (HLL)

- Circumference of breast immediately behind the front limb (CB)

- Circumference of the metacarpus (CMc)

- Circumference of the metatarsus (CMt)

- Carcass weight (CW)

The bodies were laid sideways for measuring (Figure 2):

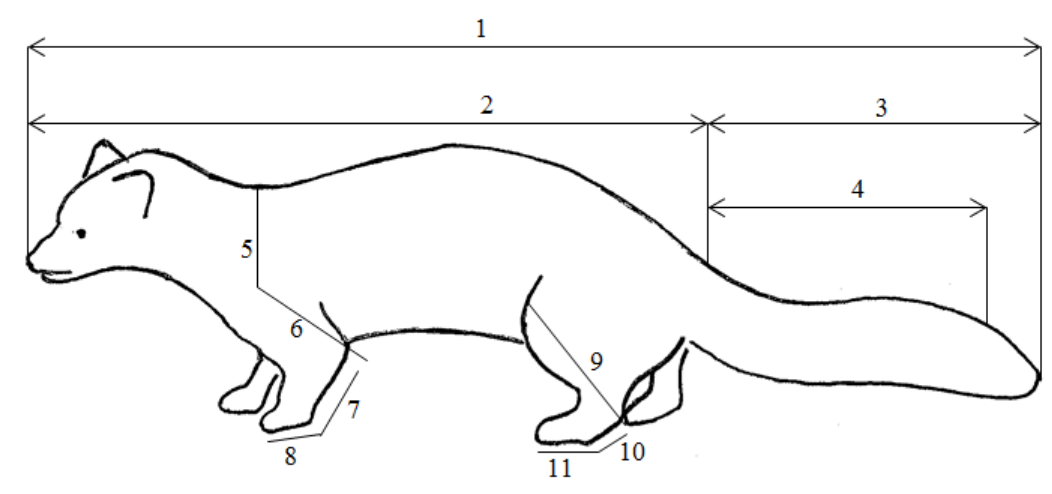

Figure 2. Some of the linear parameters taken on Stone Marten: 1 - TBL; 2 - BL; 3 - LTh; 4 - LT; 5+6 - FLL1; $7+8-$ FLL2; 9+10+11 - HLL (Because of limb measuring in straighten position, combining some of the characters was needed)

A flexible measuring tape was used to obtain the linear parameters (to the nearest of $0,1 \mathrm{~cm}$ ) and an electronic scales - for the carcass weight (up to $5 \mathrm{~g}$ ).
The variability of the linear parameters and the level of statistically significance of the differences between sexes were processed by STATISTICA 6.0 software (StatSoft Inc., 2002). 
Sexual dimorphism was defined two ways: as a ratio: male parameter/female parameter and as a percentage: the parameter difference between sexes/female value x 100 .

The differences between sexes in compactness index (CB/BL and $\mathrm{CB} / \mathrm{BLs})$ were found.

\section{RESULTS AND DISCUSSION}

The data revealed that the most variable body parameters in male stone martens from Sarnena Gora Mts were: LT ( $\mathrm{Vc}=6.51)$; FLL1 $(\mathrm{Vc}=7.86)$ and $\mathrm{CB}(\mathrm{Vc}=8.6$; Table 1).

Table 1. Basic statistical characteristic for measured body parameters of male stone martens from Sarnena Sredna Gora Mts

\begin{tabular}{ccccccc}
\hline Parameter & $\mathrm{N}$ & Mean & Minimum & Maximum & Std.Dev. & Vc \\
\hline TBL, cm & 40 & 81,83 & 78,00 & 87,00 & 2,06 & 2,52 \\
TBLs, cm & 40 & 80,78 & 76,00 & 86,00 & 2,22 & 2,75 \\
BL, cm & 41 & 49,11 & 43,00 & 55,00 & 2,08 & 4,23 \\
BLs, cm & 41 & 47,38 & 43,00 & 51,00 & 1,67 & 3,51 \\
LTh, cm & 40 & 33,40 & 29,00 & 37,00 & 1,69 & 5,07 \\
LT, cm & 40 & 24,78 & 22,00 & 29,00 & 1,61 & 6,51 \\
FLL1, cm & 24 & 9,56 & 8,50 & 11,00 & 0,75 & 7,86 \\
FLL2, cm & 24 & 12,69 & 11,50 & 14,50 & 0,69 & 5,43 \\
HLL, cm & 24 & 16,09 & 15,00 & 18,20 & 0,83 & 5,12 \\
CB, cm & 41 & 25,13 & 21,00 & 30,00 & 2,16 & 8,60 \\
CMc, cm & 24 & 7,03 & 6,50 & 7,50 & 0,28 & 3,97 \\
CMt, cm & 24 & 6,95 & 6,30 & 7,40 & 0,23 & 3,32 \\
CW, g & 41 & 1648,05 & 1100,00 & 2500,00 & 314,85 & 19,11 \\
\hline
\end{tabular}

In females, except these three parameters, high values of variability showed: LTh $(\mathrm{Vc}=6.09)$; $\mathrm{CMc}(\mathrm{Vc}=8.55)$ and $\mathrm{CMt}(\mathrm{Vc}=10.85$; Table 2). The mean carcass weight in males was $1648 \mathrm{~g}$, varying between 1100 and $2500 \mathrm{~g}$ (Table 1). The females were lighter with an average weight
$1335 \mathrm{~g}(900-1800 \mathrm{~g}$; Table 2). This was the most variable parameter compared to other studied linear parameters. The same as obtained results, 14 were found that in Hungary the adult male stone martens were significantly bigger than females - mean body weight in males was 1705 $\mathrm{g}$ and in female $-1309 \mathrm{~g}$.

Table 2. Basic statistical characteristic for measured body parameters of female stone martens from Sarnena Sredna Gora Mts

\begin{tabular}{ccccccc}
\hline Parameter & N & Mean & Minimum & Maximum & Std.Dev. & Vc \\
\hline TBL, cm & 23 & 79,61 & 74,00 & 87,00 & 3,27 & 4,11 \\
TBLs, cm & 23 & 78,61 & 72,00 & 85,00 & 3,16 & 4,02 \\
BL, cm & 24 & 46,56 & 44,00 & 50,00 & 1,70 & 3,66 \\
BLs, cm & 24 & 45,29 & 43,00 & 48,00 & 1,47 & 3,25 \\
LTh, cm & 23 & 33,22 & 30,00 & 38,00 & 2,02 & 6,09 \\
LT, cm & 23 & 24,24 & 22,00 & 28,00 & 1,54 & 6,34 \\
FLL1, cm & 18 & 8,64 & 7,50 & 10,50 & 0,75 & 8,61 \\
FLL2, cm & 18 & 11,63 & 10,50 & 12,50 & 0,57 & 4,89 \\
HLL, cm & 18 & 15,42 & 14,50 & 17,00 & 0,73 & 4,75 \\
CB, cm & 24 & 22,94 & 19,00 & 26,50 & 2,19 & 9,56 \\
CMc, cm & 18 & 6,71 & 6,00 & 8,00 & 0,57 & 8,55 \\
CMt, cm & 18 & 6,54 & 5,70 & 8,00 & 0,71 & 10,85 \\
CW, g & 24 & 1335,83 & 900,00 & 1800,00 & 236,18 & 17,68 \\
\hline
\end{tabular}



All of the studied body parameters, except LTh and LT, differed between males and females (Table 3). Thus, males were characterized with more massive and compact body (proved by index of compactness; Table 3) with longer limbs than females. An obvious difference in sexual dimorphism rate between BL
- 5.47\% and TBL - 2.78 was estimated (Table 3). Length of the tail (with or without hairs), a part of the Total Body Length, didn't demonstrate sexual differences due to its high variability. Maybe the tail length is an individual feature that doesn't depend on the sex.

Table 3. Sexual dimorphism in body parameters and compactness index of the Stone Marten from Sarnena Sredna Gora Mts, expressed as a ratio: male parameter/female parameter and as a percentage: the parameter difference between sexes/female value $x 100$.

\begin{tabular}{cccccc}
\hline Parameter & Mean/males & Mean/females & $\mathrm{p}$ & male/female ratio & $\begin{array}{c}\text { dimorphism rate } \\
\%\end{array}$ \\
\hline TBL, cm & 81,83 & 79,61 & 0,002 & 1,03 & 2,78 \\
TBLs, cm & 80,78 & 78,61 & 0,002 & 1,03 & 2,76 \\
BL, cm & 49,11 & 46,56 & 0,000 & 1,05 & 5,47 \\
BLs, cm & 47,38 & 45,29 & 0,000 & 1,05 & 4,61 \\
LTh, cm & 33,40 & 33,22 & 0,702 & 1,01 & 0,55 \\
LT, cm & 24,78 & 24,24 & 0,202 & 1,02 & 2,21 \\
FLL1, cm & 9,56 & 8,64 & 0,000 & 1,11 & 10,63 \\
FLL2, cm & 12,69 & 11,63 & 0,000 & 1,10 & 9,12 \\
HLL, cm & 16,09 & 15,42 & 0,009 & 1,04 & 4,38 \\
CB, cm & 25,13 & 22,94 & 0,000 & 1,10 & 9,57 \\
CMc, cm & 7,03 & 6,71 & 0,023 & 1,05 & 4,74 \\
CMt, cm & 6,95 & 6,54 & 0,012 & 1,06 & 6,22 \\
CW, g & 1648,05 & 1335,83 & 0,000 & 1,23 & 23,37 \\
CB/BL $(\%)$ & 51,29 & 49,33 & 0,139 & 1,04 & 3,89 \\
CB/BLs $(\%)$ & 53,09 & 50,69 & 0,058 & 1,05 & 4,75 \\
\hline
\end{tabular}

In the present study the highest percentage of sexual dimorphism was found in carcass weight. Male stone martens were $23.37 \%$ heavier than females (Table 3). 15 estimated sexual size dimorphism rate in weight for mustelids as: $\log$ $(\mathrm{x} / \mathrm{y})=\log \mathrm{x}-\log \mathrm{y}($ following $16 ; 17)$ and found out that in Stone Marten it was 0.1. The transformed data for carcass weight from the present study were similar (0.09). In accordance, 18; 19 reported that male stone martens weight with $350 \mathrm{~g}$ more than females, and for pine martens these differences were around $400 \mathrm{~g}$.

\section{CONCLUSIONS}

- There was found sexual size dimorphism in body size of Stone Marten from Central Bulgaria: males were larger than females.

- The tail length (with or without hairs) of Stone Marten did not depend on sex.

- The sexual dimorphism in the most variable linear parameters of the species varied from $2.76 \%$ to $10.63 \%$.

\section{ACKNOWLEDGEMENTS}

The help of assoc. prof. Evgeniy Raichev, $\mathrm{PhD}$ in methodological work and collaboration of hunters in providing the samples is greatly acknowledged.

\section{REFERENCES}

1. Takeuchi, M., Sexual dimorphism and relative growth of body size in the Japanese red fox Vulpes vulpes japonica. Mammal Study, 35: 125-131, 2010.

2. Brown, J., Lasiewski, R., Metabolism of weasels: the cost of being long and thin. Ecology, 53: 939-943, 1972.

3. Erlinge, S., Adaptive significance of sexual dimorphism in weasels. Oikos, 33: 233-245, 1979.

4. Moors, P., Sexual dimorphism in the body size of mustelids (Carnivora): the roles of food habits and breeding systems. Oikos, 34: 147-158, 1980.

5. King, C., Powell, R., The natural history of weasels and stoats. Ecology, Behavior and Management. Oxford University Press, New York, 446 p., 2007.

6. Roper, T., Badger. Harper Collins Publishers, London, 386 p., 2010.

7. Law for hunting and protection of the game, DV, 62/12 July 2013 (BG).

8. Popov, V., Sedefchev, A., Mammals in Bulgaria. Geosoft EOOD, 291 p., 2003. (BG)

9. Peshev, Ts., Peshev, D., Popov V., Fauna 
Bulgaria, 27, Mammalia. Edito Academica, Marin Drinov, 644 p., 2004. (BG)

10.Hall, R., American weasels. University Kansas Museum of Natural Hystory Publ., 4: 1-466, 1951.

11.Lynch, J., Conroy, A., Kitchener, D., Jefferies, D., Hayden, T., Variation in cranial form and sexual dimorphism among five European populations of the otter Lutra lutra (L.). Journal of Zoology (London), 238: 8196, 1996.

12.Peel, M., Finlayson, B., McMachon, T., Updated world map of the Köppen-Geiger climate classification. Hydrology and Earth System Sciences, 11:1633-1644, 2007.

13.Raichev, E., Peeva, S., Masuda, R., Kaneko, Y., Tsunoda, H., Georgiev, D., Georgiev, D., Sexual dimorphism in body parameters of the golden jackal Canis aureus L., 1758 (Carnivora, Canidae) in the Sarnena Sredna Gora Mountain and Thracian plain (Bulgaria). Trakia Journal of Sciences, 2: 135-140, 2017. 14.Lanszki, J., Valkar, B., Data for external morphometry of stone marten, polecat and weasel in Hungary. Natura Somogyiensis, 15: 227-230, 2009.

15. Berdnikovs, S., Evolution of sexual dimorphism in Mustelids, B. S., University of Latvia, PhD Thesis, 205 p., 2005.

16. La Barbera, M., Analysing body size as factor in ecology and evolution, Annual Review of Ecology and systematics, 20: 97-117, 1989.

17. Ranta, E., Laurila, A., Elmberg, J., Reinventing the wheel: analysis of sexual dimorphism in body size, Oikos, 71: 313-321, 1994.

18. König, R., Müller, F., Morphologische Untersuchungen am mitteleuropäischen Baummarder (Martes martes L., 1758) und Steinmarder (Martes foina Erxl., 1777), I. Jagd und Hege, 4: 31-33, 1986a.

19. König, R., Müller, F., Morphologische Untersuchungen am mitteleuropäischen Baummarder (Martes martes L., 1758) und Steinmarder (Martes foina Erxl., 1777), II. Jagd und Hege, 5: 17 -19, 1986b. 